Article

\title{
Synthesis, Characterization and in Vitro Evaluation of New Composite Bisphosphonate Delivery Systems
}

\author{
Joanna Kolmas ${ }^{1, \dagger}$, Marcin Sobczak ${ }^{1, *}$, Ewa Olędzka ${ }^{1, \dagger}$, Grzegorz Nałęcz-Jawecki ${ }^{2, \dagger}$ \\ and Cezary Dębek ${ }^{3, \dagger}$
}

1 Department of Inorganic and Analytical Chemistry, Faculty of Pharmacy, Medical University of Warsaw, ul. Banacha 1, 02-097 Warsaw, Poland;

E-Mails: joanna.kolmas@wp.pl (J.K.); eoledzka@wp.pl (E.O.)

2 Department of Environmental Health Science, Faculty of Pharmacy, Medical University of Warsaw, ul. Banacha 1, 02-097 Warsaw, Poland; E-Mail: gnalecz@wum.edu.pl

3 Institute for Engineering of Polymer Materials and Dies, ul. Marii Skłodowskiej-Curie 55, 87-100 Toruń, Poland; E-Mail: c.debek@ipgum.pl

$\dagger$ These authors contributed equally to this work.

* Author to whom correspondence should be addressed; E-Mail: marcin.sobczak@wp.pl; Tel.: +48-22-572-07-55; Fax: +48-22-572-07-84.

Received: 14 June 2014; in revised form: 5 August 2014 / Accepted: 12 September 2014 / Published: 22 September 2014

\begin{abstract}
In this study, new composite bisphosphonate delivery systems were obtained from polyurethanes (PUs) and nanocrystalline hydroxyapatite (HA). The biodegradable PUs were first synthesized from poly(e-caprolactone) diols (PCL diols), poly(ethylene adipate) diol, 1,6-hexamethylene diisocyanate, 1,4-butanediol and HA. Moreover, the PCL diols were synthesized by the ring-opening polymerization catalysed by the lipase from Candida antarctica. Next, composite drug delivery systems for clodronate were prepared. The mechanical properties of the obtained biomaterials were determined. The cytotoxicity of the synthesized polymers was tested. The preliminary results show that the obtained composites are perspective biomaterials and they can be potentially applied in the technology of implantation drug delivery systems.
\end{abstract}

Keywords: polymeric biomaterials; bisphosphonates; polyurethanes; hydroxyapatite; drug delivery systems; clodronate 


\section{Introduction}

Bone metastasis is prevalent in many cancers, especially breast, prostate or lung cancer, the most common neoplasms in the world today [1,2]. Cancer patients with bone metastasis are exposed to numerous skeletal disorders, such as unexpected pathological fractures, serious hypercalcaemia or severe bone pain which is difficult to relieve [1]. Until now, the first-line treatment for bone metastasis has administered bisphosphonates (BPs) [1-4]. Their mechanism of action is now more clear [5-7]. It is commonly known that they inhibit bone resorption by suppressing osteoclastogenesis and osteoclast activity via the farnesyl pyrophosphate synthase enzyme (FPPS) in the mevalonic acid pathway [6,7]. Moreover, recent research shows that BPs may inhibit bone tumour growth and tumour cell invasion in the extracellular matrix. These studies suggest a preventive role played by BPs in tumour metastasis in bone tissues [8,9].

Among the most effective BPs in bone metastasis treatment are: clodronate (CLO), pamidronate, ibandronate and zoledronic acid [2,5,10]. They are administered to patients via two routes-oral or intravenous - though unfortunately they can cause some side effects, such as an acute systemic inflammatory reaction, ocular inflammation, nephrotic syndrome or electrolyte imbalance [11]. Moreover, when applied orally, the bioavailability of these drugs is very low and often insufficient. Thus, it seems reasonable to deliver BPs locally and as a consequence accelerate their local bioavailability.

It should be emphasized that the therapeutic efficacy of BPs administered by standard methods is also limited. In recent years, unconventional macromolecular drug delivery systems (DDS) have became the focus of interest [12-14]. Polymeric DDS exhibit unique pharmacokinetics, distribution and pharmacological efficacy. Numerous BP delivery systems (BPDDS) have been investigated [15-23]. They include dendrimeric polymers, hydrogels, liposomes, nanocapsules, nanospheres and macromolecular conjugates. One particularly interesting kind of BPDDS comprises biomaterials used as orthopaedic implants $[15,16]$.

Aliphatic or cycloaliphatic polyurethanes (PUs) demonstrate good biodegradability and biocompatibility in human tissues. These attributes make them advantageous and extremely useful for the technology of controlled DDS [14,24].

Until now, the studies into BPDDS have been carried out mostly using animal models, with only a few exceptions employing human clinical trials. As such, the preparation of novel BPDDS is especially interesting for the pharmaceutical industry and medicine in general.

Moreover, it is important to know that BPs exhibit a strong affinity to nanocrystalline hydroxyapatites $[25,26]$. It has been shown that they may strongly adsorb on the apatitic surface by an ion-exchange mechanism between phosphonate groups from BPs and phosphate ions from hydroxyapatite (HA) [27]. Several authors have reported that some BPs may also adsorb on HA through surface binding of phosphonate groups and $\mathrm{Ca}^{2+}$ sites of HA $[25,28]$. Therefore, the use of HA nanoparticles as the delivery system of BPs has been widely studied [29,30].

The main aim of our study has been to prepare composite CLO DDS using biodegradable PUs hydroxyapatite (HA) as components. The structures and chemical compositions of the new biomaterials were investigated and discussed based on the results obtained. 


\section{Results and Discussion}

\subsection{Synthesis of Polyols and Polyurethanes}

The aim of the first part of this study was to obtain poly( $\varepsilon$-caprolactone) diols (PCL diols) which could be applied as precursor of further polyurethanes (PUs) synthesis. The polymerization reactions of $\varepsilon$-caprolactone (CL) in the presence of diethylene glycol (DEG) and the lipase from Candida antarctica (CA) were conducted at $70{ }^{\circ} \mathrm{C}$ for 14 days. The molar ratio of CL/DEG was either 20:1 (PCL-1), 30:1 (PCL-2) or 40:1 (PCL-3). Reactions were carried out with one level of lipase concentration at the same scale of monomer (100 $\mathrm{mg}$ of CA).

The structure of the obtained PCL diols was confirmed by proton nuclear magnetic resonance $\left({ }^{1} \mathrm{H}\right.$ NMR) or carbon-13 nuclear magnetic resonance $\left({ }^{13} \mathrm{C} \mathrm{NMR}\right)$, Fourier transform infrared spectroscopy (FTIR) and matrix-assisted laser desorption/ionization mass spectrometry (MALDI-TOF MS) (Experimental Section).

In the MALDI-TOF MS spectra of the PCL diols, linear macromolecules were observed (Figure 1). The first and most prominent series of peaks was assigned to polyols terminated with a hydroxyl group (residual mass: $15 \mathrm{Da}, \mathrm{Na}^{+}$adduct). This series of peaks was differing by $114 \mathrm{Da}$, which is equal to the mass of the repeating unit of PCL. In addition, low-intensity series of peaks corresponding to macromolecules (residual mass: $31 \mathrm{Da}, \mathrm{K}^{+}$adduct) was detected in the mass spectrum. The average molecular mass $\left(M_{n}\right)$ values of PCL diols determined by the MALDI-TOF MS method ranged from 1500 to $2900 \mathrm{Da}$ (polydispersity indexes $(P D)$ 1.36-1.89).

Figure 1. Matrix-assisted laser desorption/ionization mass spectrometry (MALDI-TOF MS) spectrum of poly( $\varepsilon$-caprolactone) diol.

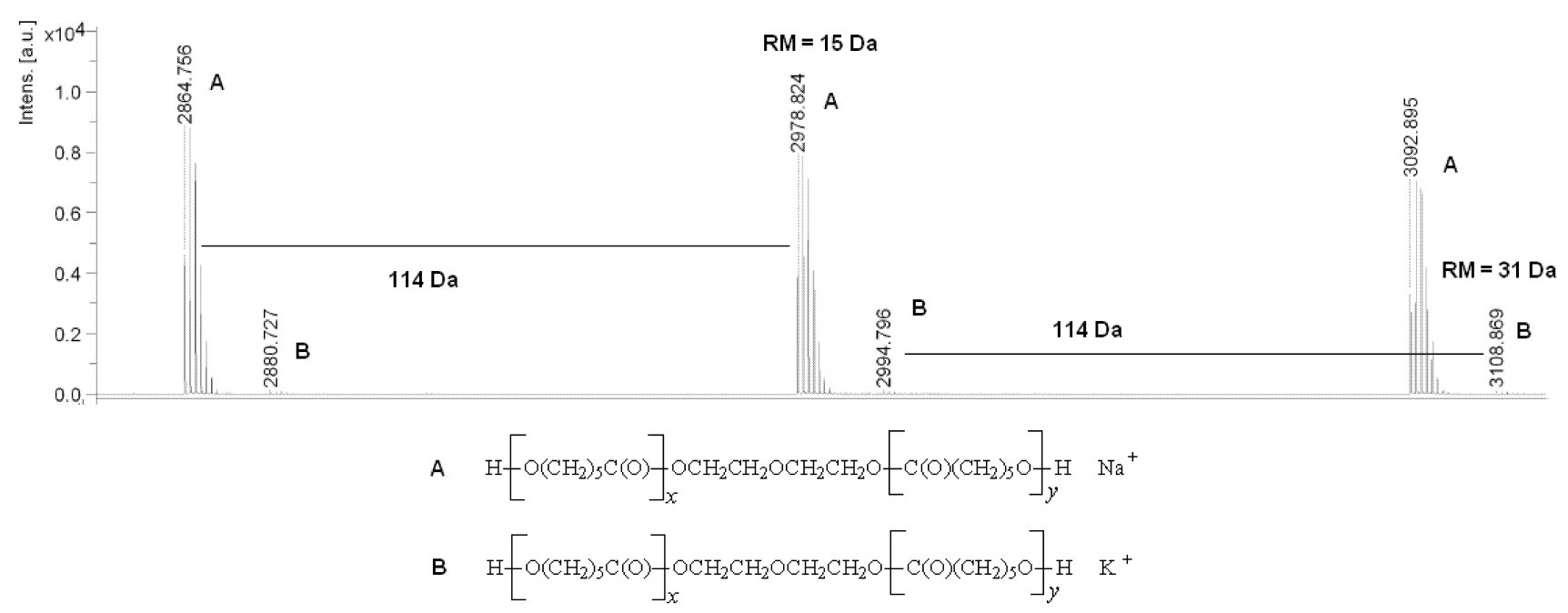

The weight method was used to determine the reaction yield. For the PCL-1, PCL-2 and PCL-3, the corresponding yield values were $84 \%, 73 \%$ and $69 \%$, respectively.

The $M_{n}$ values of the PCL diols determined by the gel permeation chromatography (GPC) method were 1800 (PCL-1), 2400 (PCL-2) and 3200 Da (PCL-3), respectively, while the PD showed small variations (between 1.42 and 1.63). 
The PUs were obtained using PCL diols, dihydroxy(polyethylene adipate) (PEAD) as the soft segments, and 1,6-hexamethylene diisocyanate (HMDI) and 1,4-butanediol (BD) as components of the hard segments. 1,4-diazabicyclo[2.2.2] octane (DABCO) was used as the polyaddition catalyst. A two-step melt polymerization procedure was engaged to this process. The isocyanate index (isocyanate to hydroxyl equivalent ratio) was 1.05 . The molar ratio of $\mathrm{HMDI} / \mathrm{BD} / \mathrm{PEAD} / \mathrm{PCL} / \mathrm{DABCO}$ was 2.5:0.9:0.8:0.8:0.01. The $M_{v}$ values of the PUs were evaluated by the viscosity method and were within the range of 58,000-62,000 g/mol (Table 1).

Table 1. Characterization of synthesized polyurethanes.

\begin{tabular}{cccccccc}
\hline No. & PU & Reagents & $\begin{array}{c}\boldsymbol{M}_{\boldsymbol{v}} \\
(\mathbf{g} / \mathbf{m o l})\end{array}$ & $\boldsymbol{F}_{\boldsymbol{S}}$ (MPa) & $\begin{array}{c}\boldsymbol{S}_{\mathbf{1 0 0}} \\
(\mathbf{M P a})\end{array}$ & $\boldsymbol{\varepsilon}(\mathbf{\%})$ & $\begin{array}{c}\boldsymbol{S h}_{\boldsymbol{H}} \\
(\text { Shore A) }\end{array}$ \\
\hline 1. & PU-1 & HMDI/BD/PEAD/PCL-1 & 62,100 & $14.7 \pm 0.8$ & $5.2 \pm 0.3$ & $312 \pm 12$ & $44 \pm 3$ \\
2. & $\mathbf{P U - 2}$ & HMDI/BD/PEAD/PCL-2 & 58,200 & $14.3 \pm 0.9$ & $5.4 \pm 0.3$ & $348 \pm 13$ & $42 \pm 3$ \\
3. & $\mathbf{P U - 3}$ & HMDI/BD/PEAD/PCL-3 & 59,600 & $13.9 \pm 0.7$ & $5.5 \pm 0.2$ & $358 \pm 11$ & $41 \pm 2$ \\
\hline
\end{tabular}

$M_{v}-$ calculated from the Mark-Houwink equation using the following constants: $\mathrm{K}=6.80 \times 10^{-5} \mathrm{dL} / \mathrm{g}$ and $\alpha=0.86 ; F_{S}$-fail stress; $S_{100}$-stress at $100 \%$ elongation; $\varepsilon$ —elongation at break; $S h_{H}$-Shore hardness.

The chemical structure of the PUs was confirmed by ${ }^{1} \mathrm{H},{ }^{13} \mathrm{C}$ NMR and FTIR (Figures 2 and 3). The data are shown in the Experimental Section.

Table 1 shows the mechanical properties of the obtained PUs. The fail stress $\left(F_{S}\right)$, stress at 100\% elongation $\left(S_{100}\right)$, Shore hardness $\left(S h_{H}\right)$ and stress at $100 \%$ elongation at break $(\varepsilon)$ of the obtained PUs were determined. As is presented in Table 1, the $\varepsilon$ was greater than $300 \%$. The obtained materials showed $F_{S}$ within the range of 13.9-14.7 MPa and $S h_{H}$ within the range of 41-44 Shore A degrees.

Figure 2. Structure of the obtained polyurethanes.
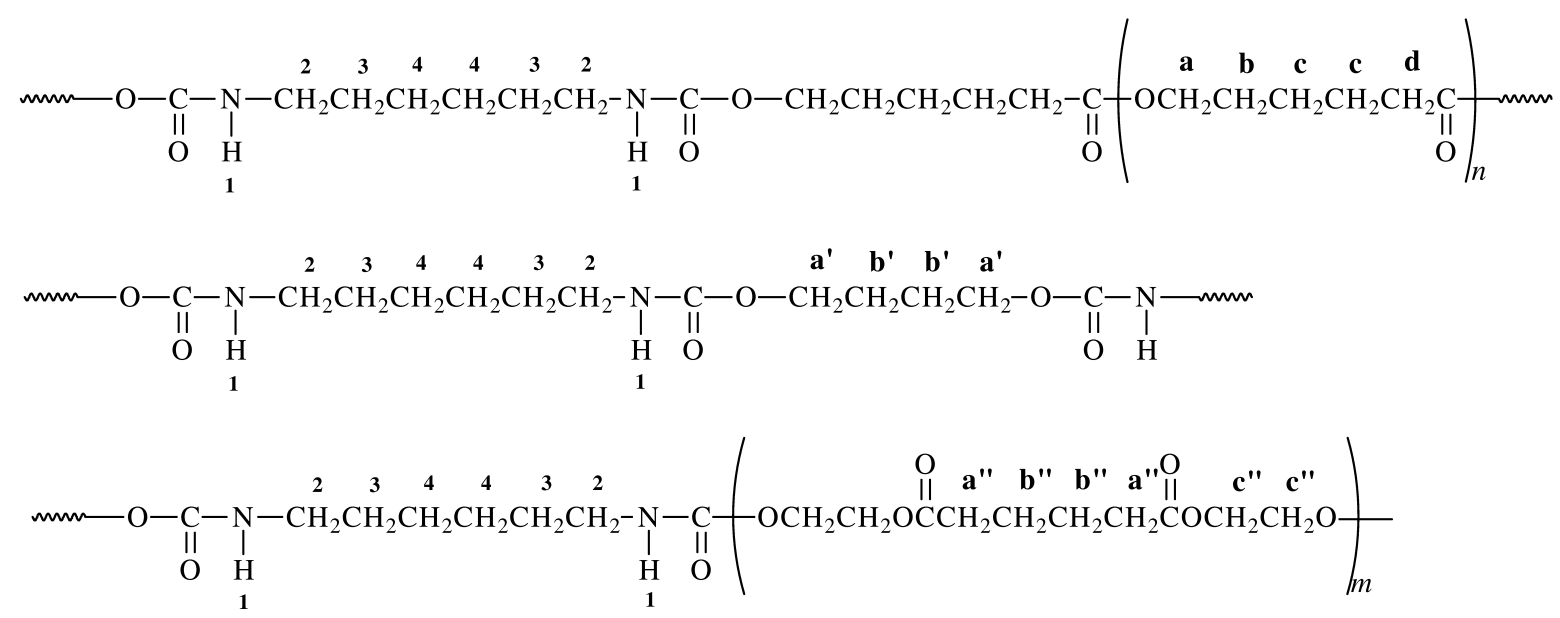
Figure 3. ${ }^{1} \mathrm{H}$ NMR spectrum of the obtained polyurethane (DMSO-d6).

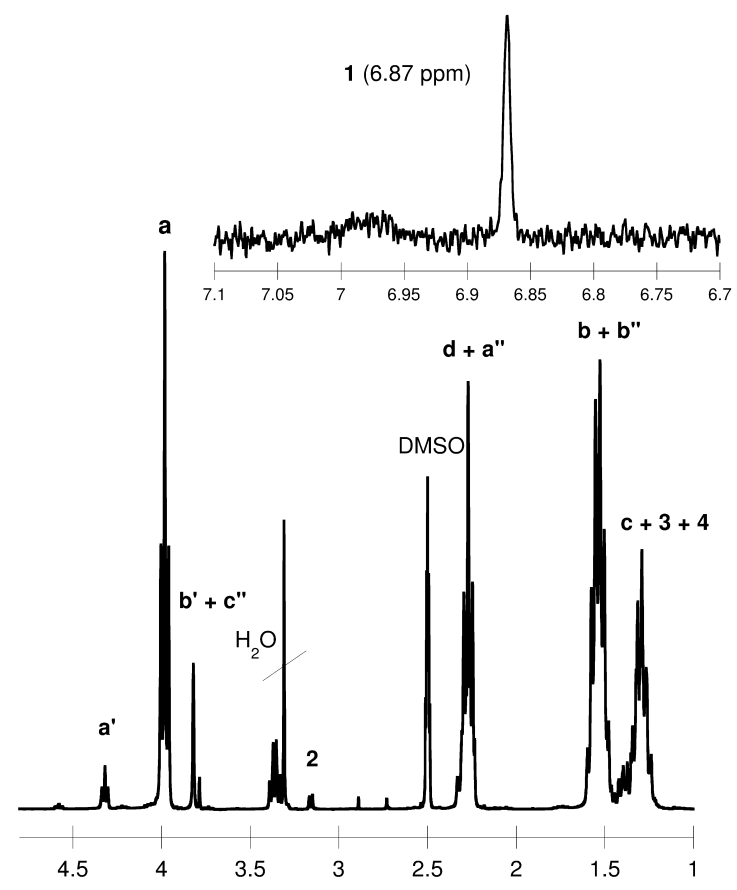

\subsection{The Polyurethane/Hydroxyapatite Composites' Fabrication}

The polyurethane/hydroxyapatite composites (PU-HA composites) were obtained from previously synthesized PU-1, PU-2 and PU-3 (Table 2). The ratio of PU to HA was 9:1 or 8:2 (w/w) (Figure 4). The composites were formed by mixing the mixture of PU and nanocrystalline $\mathrm{HA}$ with $\mathrm{NaCl}$. The size of the HA crystals used varied from 15 to $40 \mathrm{~nm}$ (Figure 5).

Table 2. Characterization of polyurethane/hydroxyapatite composites.

\begin{tabular}{ccccc}
\hline No. & Code & Composition & $\boldsymbol{d}\left(\mathbf{g} / \mathbf{c m}^{\mathbf{3}}\right)$ & $\boldsymbol{P ( \% )}$ \\
\hline 1. & PU-HA-1 & PU-1(PCL-1)/HA: 9/1 & $0.225 \pm 0.003$ & $66.5 \pm 0.9$ \\
2. & PU-HA-2 & PU-1(PCL-1)/HA: 8/2 & $0.266 \pm 0.003$ & $53.6 \pm 0.6$ \\
3. & PU-HA-3 & PU-2(PCL-2)/HA: 9/1 & $0.210 \pm 0.002$ & $59.4 \pm 0.6$ \\
4. & PU-HA-4 & PU-2/HA PU(PCL-2): 8/2 & $0.259 \pm 0.002$ & $46.4 \pm 0.4$ \\
5. & PU-HA-5 & PU-3(PCL-3)/HA: 9/1 & $0.207 \pm 0.002$ & $56.2 \pm 0.5$ \\
6. & PU-HA-6 & PU-3(PCL-3)/HA: 8/2 & $0.244 \pm 0.003$ & $42.2 \pm 0.5$ \\
\hline
\end{tabular}

$d$ - the density of the composite; $P$-amount of open pores in the composite.

Figure 4. Representative image of the polyurethane/hydroxyapatite composite.

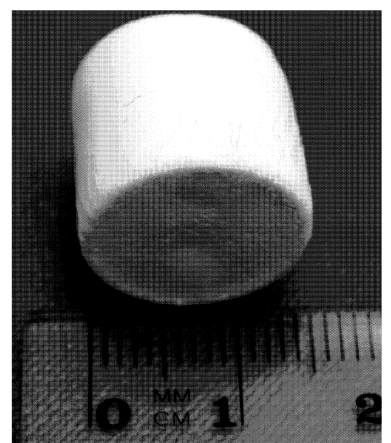


Figure 5. Transmission electron microscope (TEM) image of the hydroxyapatite used as components of the composites.

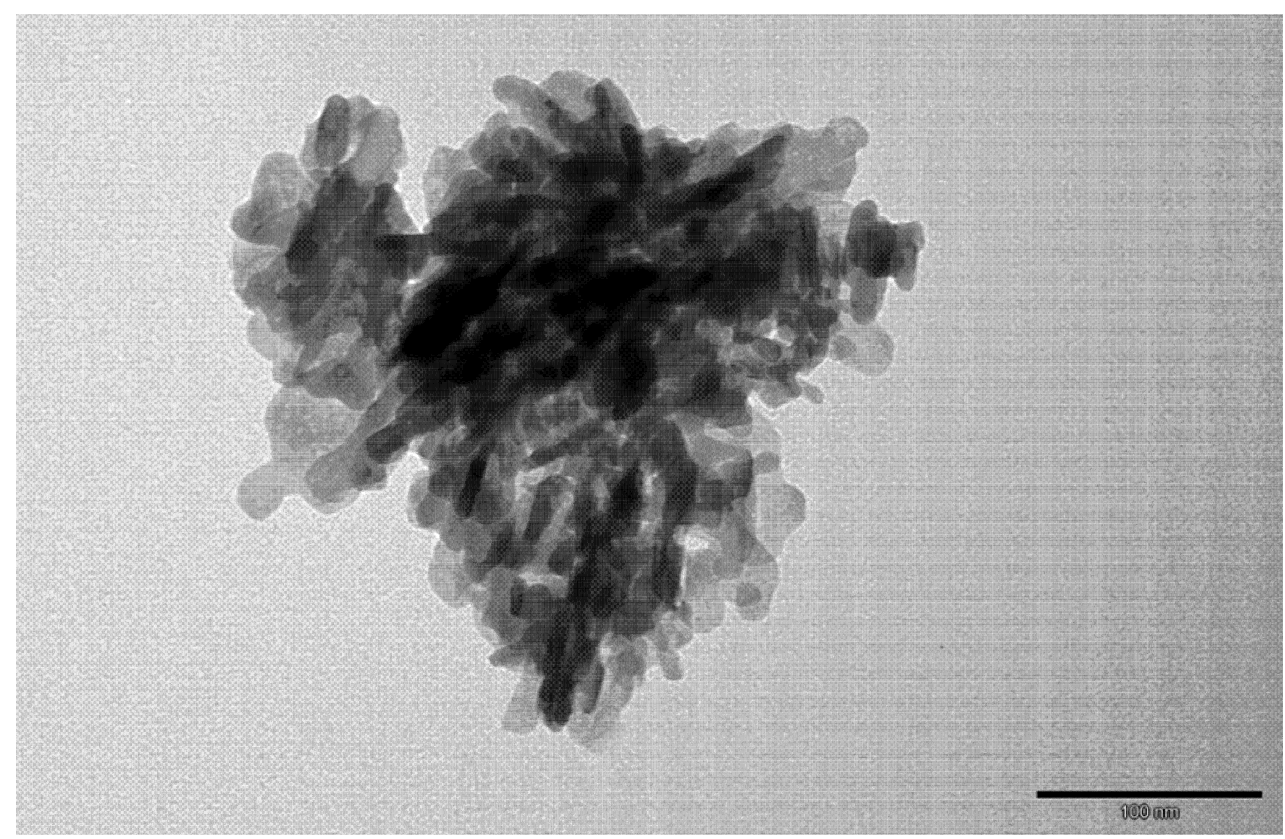

The density $(d)$ increased with HA content. The $d$ values were ranged from 0.207 to $0.266 \mathrm{~g} / \mathrm{cm}^{3}$. In parallel, the porosity $(P)$ of the PU-HA composites decreased when HA content increased. For example, the $P$ of PU-HA-1 and PU-HA-2 was $66.5 \%$ and $53.6 \%$, respectively.

A typical scanning electron microscope (SEM) micrograph of the PU-HA composite shows the continuous structure of interconnected and somewhat regular pores (Figure 6). The regular pores range from several microns up to a dozen or so microns, which is within the appropriate range for tissue engineering.

Figure 6. Scanning electron microscope (SEM) micrograph of the polyurethane/hydroxyapatite composite.

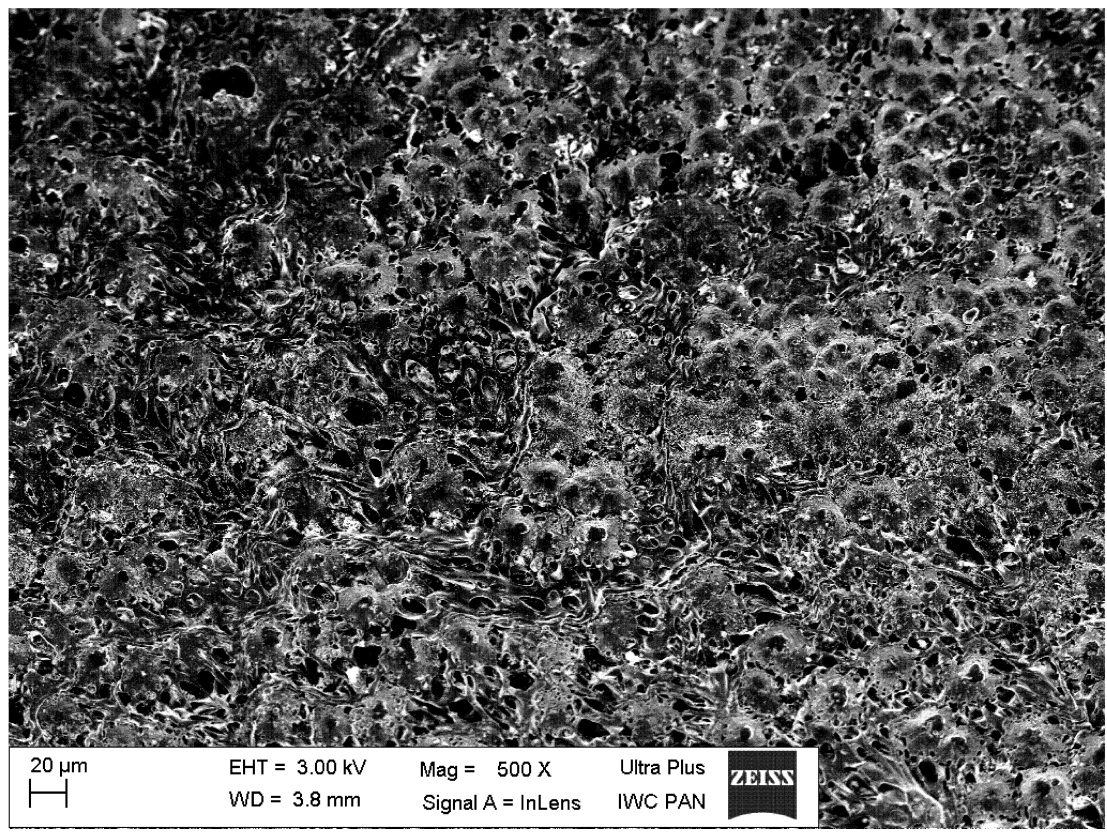




\subsection{Cytotoxic Tests}

Cytotoxic tests of the obtained PUs were carried using the luminescent bacteria $V$. fischeri and two ciliated protozoa S. ambiguum and T. termophila (Table 3). All the tested samples were not toxic to any of the tested bionts, whether bacteria or protozoa, due to the fact that a sample is considered toxic when the percentage of the toxicity effect $(P E)$ is higher than 20 .

Table 3. Cytotoxicity of the obtained polyurethanes.

\begin{tabular}{ccccccc}
\hline PU & \multicolumn{2}{c}{ Spirotox $(\mathbf{2 4} \mathbf{h})$} & \multicolumn{2}{c}{ Microtox (15 min) } & \multicolumn{2}{c}{ Protoxkit F (24 h) } \\
\hline Concentration $\left(\mathrm{mg} \cdot \mathrm{mL}^{-1}\right)$ & 10 & 1 & 1 & 0.5 & 1 & 0.5 \\
PU-1 & 0 & 0 & 0 & 0 & 15 & 5 \\
PU-2 & 0 & 0 & 0 & 0 & 14 & 8 \\
PU-3 & 0 & 0 & 0 & 0 & 16 & 11 \\
\hline
\end{tabular}

\subsection{Drug Release from the Polyurethane/Hydroxyapatite Composites}

CLO was incorporated into the PU-HA composites by immersing the material in an aqueous drug solution of a known concentration. The drug content in the PU-HA composites was $1 \% \mathrm{wt}$.

In vitro CLO release from the PU-HA composites was conducted in a phosphate buffer solution (PBS) buffer at $37^{\circ} \mathrm{C}$ for $1-8$ weeks. The kinetic rates of CLO released from the obtained biomaterials at $\mathrm{pH} 7.4$ are shown in Figures 7 and 8.

Two factors could influence the release of CLO from the obtained PU-HA composites, namely the $M_{n}$ of the PCL diols used in PU synthesis and the $P$ of the composites.

PU-HA-1 and PU-HA-2 released CLO faster compared to PU-HA-3 and PU-HA-4 or PU-HA-5 and PU-HA-6 (Figures 7 and 8). The percentage of CLO released was about 81\% for PU-HA-1, 64\% for PU-HA-3 and 36\% for PU-HA-5 after eight weeks of incubation. In comparison, the percentage of CLO released after eight weeks of incubation was around 71\% for PU-HA-2, 44\% for PU-HA-4 and 27\% for PU-HA-6.

Figure 7. Release of CLO from the PU-HA-1, PU-HA-3 and PU-HA-5 composites.

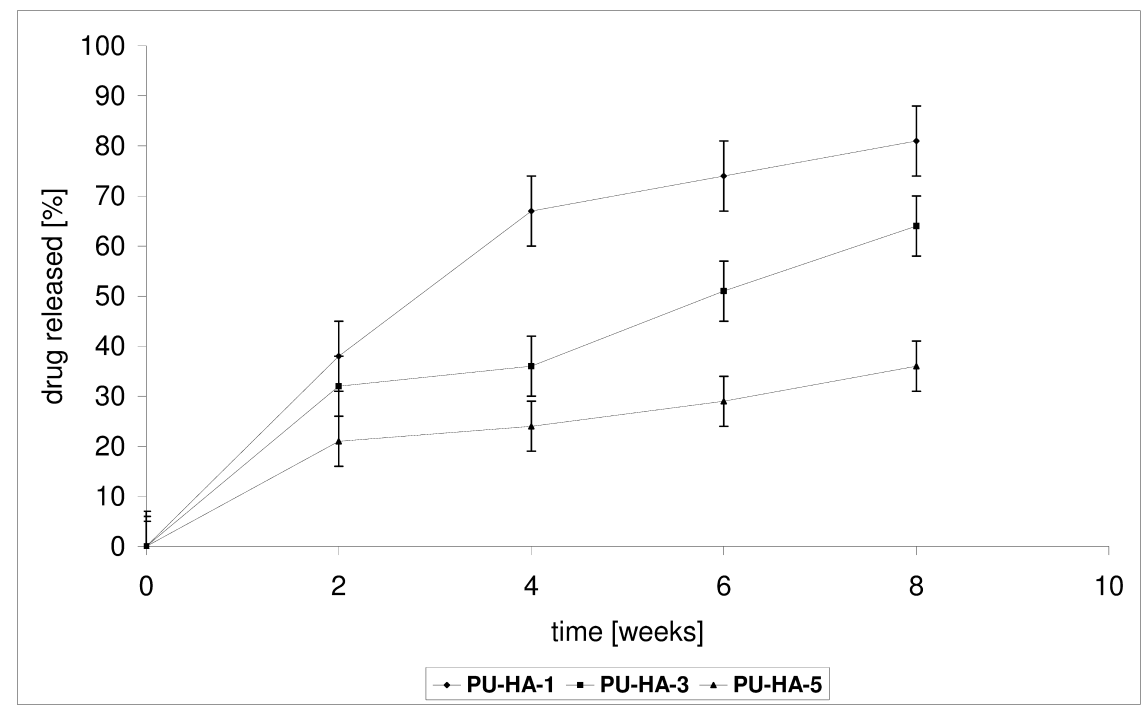


Figure 8. Release of CLO from the PU-HA-2, PU-HA-4 and PU-HA-6 composites.

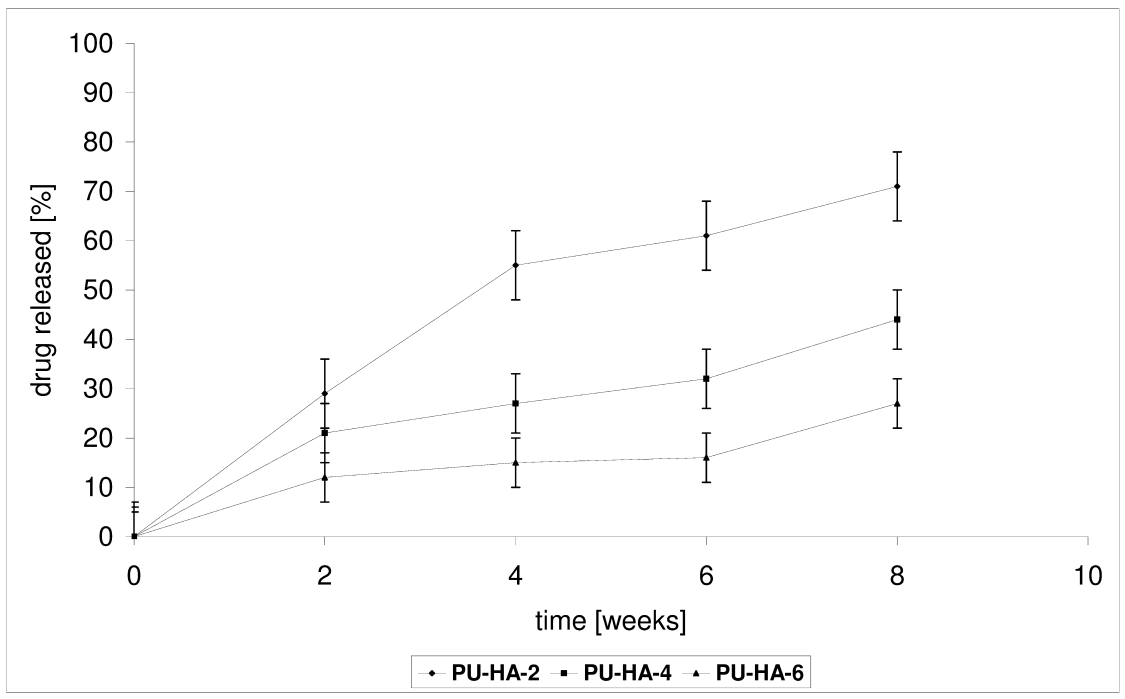

It was found that the rate of CLO release increases with increasing the $P$ and decreasing the $M_{n}$ of PCL used in PU synthesis. The $P$ of the PU-HA composites decreases with increasing HA content.

It was already known that the hydrolytic stability of PU-HA composites and CLO release from matrices depend on numerous factors, such as composition, kind of hard or soft segments, the crystallinity, and the size and form of the crystallite of the PU, etc. However, it seems that in our study the main influence on this property has a kind of polyols type soft segments.

The degradation tests of the obtained PUs or PU-HA composites and the kinetic rates of the CLO released were conducted in the same manner and under the same conditions.

The results directly comparing CLO release with the $M_{v}$ of the PUs (Table 4) or the mass loss $(W L)$ of the PU-HA matrices studies follow the same trend (Figures 9 and 10).

In vitro degradation of the synthesized PUs was controlled by the change of the mechanical properties and the $M_{v}$. The $M_{v}$ of the obtained PUs were determined after four and eight weeks of degradation (Table 4). The changes in the $M_{v}$ for the obtained PUs were around $4.7 \%-6.0 \%$ after four weeks and 7.2\%-11.4\% after eight weeks. PU-1 degraded faster in comparison to PU-2 and PU-3. The above parameters are in a good agreement with the results of the kinetic rates of CLO release from the obtained PU-HA composites.

Table 4. Molecular weight-change of the obtained polyurethanes during the in vitro degradation process.

\begin{tabular}{cccccccc}
\hline No. & PU & Reagents & $\begin{array}{c}\boldsymbol{M}_{\boldsymbol{v}} \\
(\mathbf{g} / \mathbf{m o l})\end{array}$ & $\begin{array}{c}\boldsymbol{M}_{\boldsymbol{v}(4)} \\
(\mathbf{g} / \mathbf{m o l})\end{array}$ & $\begin{array}{c}\boldsymbol{M}_{\boldsymbol{v}(4) \text { loss }} \\
\mathbf{( \% )}\end{array}$ & $\begin{array}{c}\boldsymbol{M}_{\boldsymbol{v}(\boldsymbol{8})} \\
(\mathbf{g} / \mathbf{m o l})\end{array}$ & $\begin{array}{c}\boldsymbol{M}_{\boldsymbol{v}(\boldsymbol{\delta}) \text { loss }} \\
(\mathbf{\%})\end{array}$ \\
\hline 1 & $\mathbf{P U - 1}$ & HMDI/BD/PEAD/PCL-1 & 62,100 & 58,400 & 6.0 & 55,000 & 11.4 \\
2 & $\mathbf{P U - 2}$ & HMDI/BD/PEAD/PCL-2 & 58,200 & 55,200 & 5.2 & 53,300 & 8.4 \\
3 & $\mathbf{P U - 3}$ & HMDI/BD/PEAD/PCL-3 & 59,600 & 56,800 & 4.7 & 55,300 & 7.2 \\
\hline
\end{tabular}

$M_{v}$-calculated from the Mark-Houwink equation using the following constants: $\mathrm{K}=6.80 \times 10^{-5} \mathrm{dL} / \mathrm{g}$ and $\alpha=0.86 ; M_{v(4)}$-after degradation (4 weeks); $M_{v(8)}$-after degradation (8 weeks). 
Figure 9. Mass loss of the PU-HA-1, PU-HA-3 and PU-HA-5 composites after the biodegradation process.

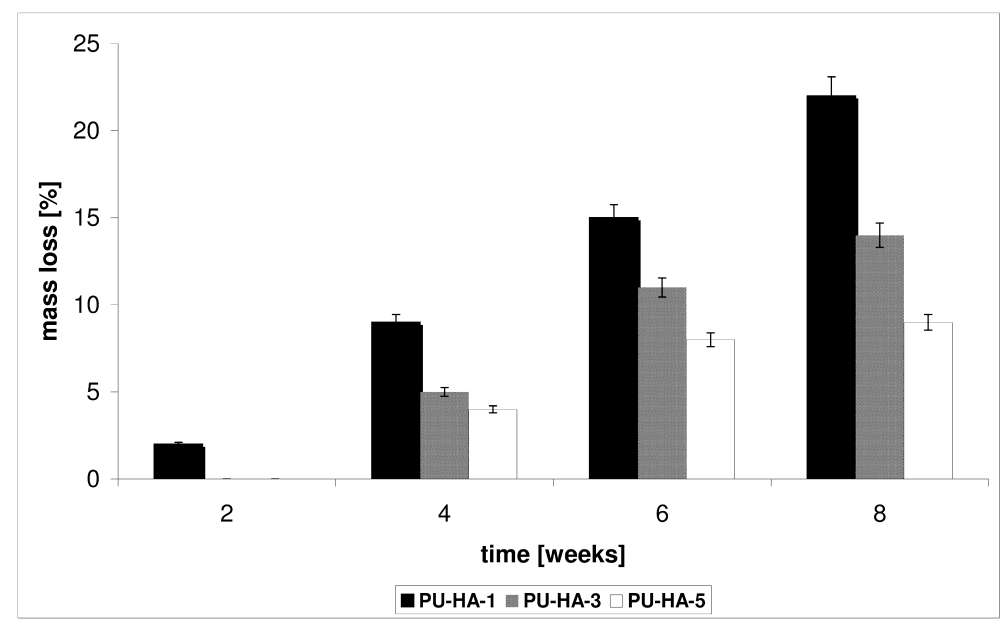

Figure 10. Mass loss of the PU-HA-2, PU-HA-4 and PU-HA-6 composites after the biodegradation process.

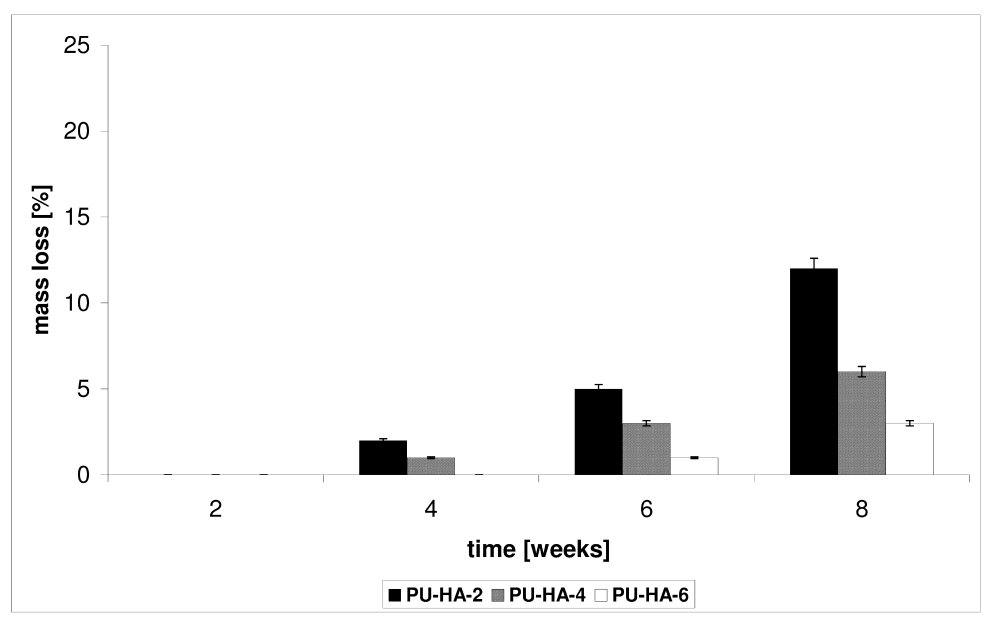

Furthermore, the kinetic rates of CLO release are in agreement with the change in the mechanical properties of the PUs and the in vitro degradation of the produced PU-HA composites. After eight weeks' degradation process, the PU-1 obtained from PCL-1 retained around $76 \%$ of the original value of $F_{S}, 84 \%$ of the value of $S h_{H}$ and $81 \%$ of the value of $\varepsilon$ (Tables 1 and 5). The changes of these parameters were clearly smaller for the PUs obtained from PCL-2 and PCL-3, which confirms earlier reports of the higher hydrolytic stability of PUs containing longer polyester units. PU-3 retained around $88 \%$ of the original value of $F_{S}, 93 \%$ of the value of $S h_{H}$ and $91 \%$ of the value of $\varepsilon$ (Table 5).

Table 5. Properties of the synthesized polyurethanes after the biodegradation process.

\begin{tabular}{ccccccc}
\hline No. & PU & Reagents & $\begin{array}{c}\boldsymbol{F}_{\boldsymbol{S}} \\
\mathbf{M P a})\end{array}$ & $\begin{array}{c}\boldsymbol{S}_{\boldsymbol{1 0 0}} \\
\mathbf{( M P a )}\end{array}$ & $\begin{array}{c}\boldsymbol{\varepsilon} \\
\mathbf{( \% )}\end{array}$ & $\begin{array}{c}\boldsymbol{S h}_{\boldsymbol{H}} \\
\text { (Shore A) }\end{array}$ \\
\hline 1. & PU-1 & HDI/BD/OEAD/PCL-1 & $11.2 \pm 0.7$ & $4.1 \pm 0.2$ & $252 \pm 10$ & $37 \pm 3$ \\
2. & PU-2 & HDI/BD/OEAD/PCL-2 & $11.7 \pm 0.8$ & $4.5 \pm 0.3$ & $296 \pm 9$ & $37 \pm 3$ \\
3. & PU-3 & HDI/BD/OEAD/PCL-3 & $12.2 \pm 0.6$ & $5.0 \pm 0.2$ & $326 \pm 11$ & $38 \pm 2$ \\
\hline
\end{tabular}

$F_{S}$-fail stress; $S_{100}$ - stress at $100 \%$ elongation; $\varepsilon$-elongation at break; $S h_{H}$-Shore hardness. 
In vitro degradation of the obtained PU-HA composites was controlled by the $W L$ of the materials. The results are shown in Figures 9 and 10. The $W L$ values of PU-HA-1 and PU-HA-2 were 22\% and $12 \%$ after eight weeks of degradation, respectively. However, for PU-HA-5 and PU-HA-6 the $W L$ was 9\% and 3\% (after eight weeks). The $W L$ values of PU-HA increased slowly with increasing hydrolytic degradation time. These results correlate well with the change in the mechanical properties of the PUs.

The scanning electron microscopic images of the PU-HA composites, both in their original state and after eight weeks' degradation process, are shown in Figure 11. In comparison to the original composite (Figure 11a), the surface of the PU-HA composite after the degradation process shows severe cracking all over its surface, indicating significant oxidative/hydrolytic damage (Figure 11b).

Figure 11. SEM micrographs of the polyurethane/hydroxyapatite composite. (a) before the degradation process; (b) after eight weeks' degradation process.

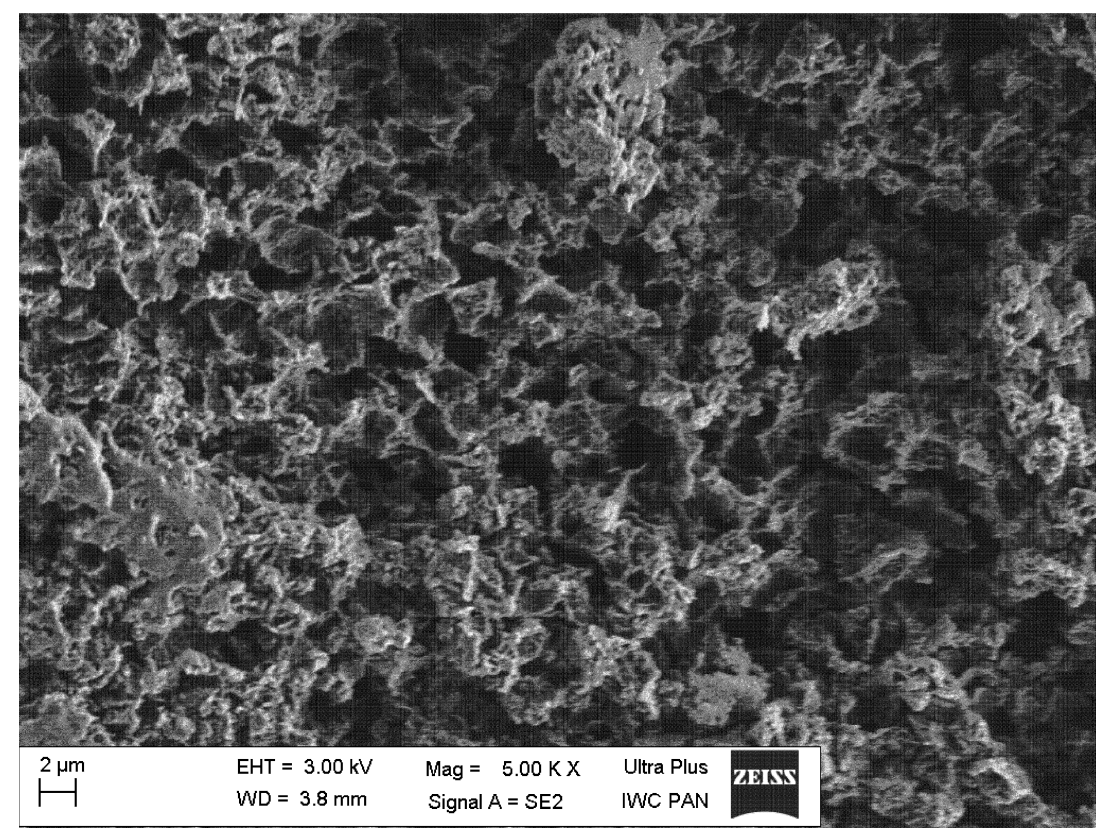

(a)

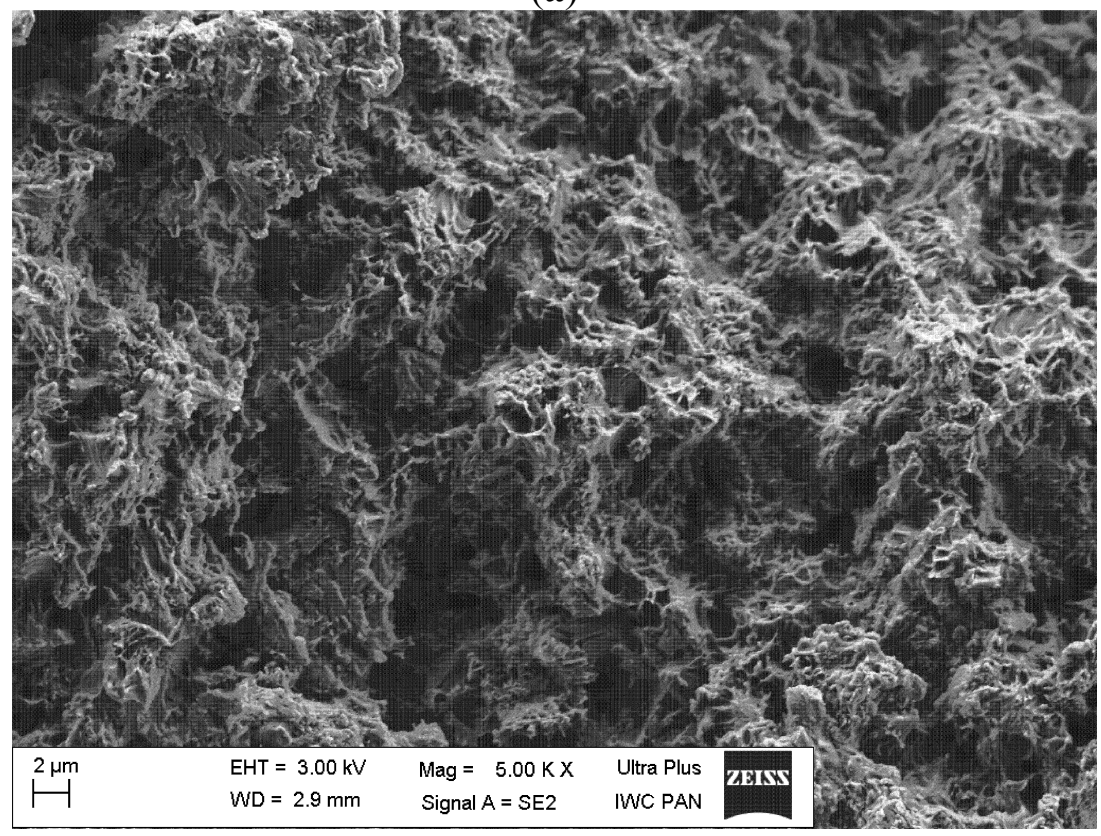

(b) 


\section{Experimental Section}

\subsection{Materials}

Lipase from Candida Antarctica (CA, Aldrich, Poznań, Poland), dichloromethane $\left(\mathrm{CH}_{2} \mathrm{Cl}_{2}\right.$, Polish Chemical Reagents, Gliwice, Poland), dimethyl sulfoxide (DMSO, 99\%, Aldrich), $N, N$-dimethylformamide (DMF, Aldrich), 2-[(4-hydroxyphenyl)diazenyl]benzoic acid (HABA) and methanol (MeOH, Polish Chemical Reagents) were used as received. 1,6-hexamethylene diisocyanate (HMDI, 98\%, Aldrich), poly(ethylene adipate) diol (PEAD diol, $M_{n}=1000$ Da, Aldrich), 1,4-butanediol (BD, 98\%, Fluka, Poznań, Poland), 1,4-diazabicyclo[2.2.2]octane (DABCO, 99\%, Aldrich), diethylene glycol (DEG, 98\%, Aldrich) and synthetic hydroxyapatite (HA, Riedle-de Haën, Poznań, Poland) were used without further purification. $\varepsilon$-Caprolactone (2-oxepanone, 99\%, CL, Aldrich) was dried and distilled over $\mathrm{CaH}_{2}$ at reduced pressure before use.

\subsection{Synthesis of Poly(E-caprolactone) Diols}

The CL, DEG and CA were weighed (under dry argon) into a cylindrical glass reactor. Before the reactions, the monomer, glycol and enzyme were dried in vacuo at room temperature for $1 \mathrm{~h}$. The reaction vessel was placed into an oil bath. Polymerization of the CL $(0.05 \mathrm{~mol})$ in the presence of DEG (0.00125-0.0025 mol) and $100 \mathrm{mg}$ CA was carried out in bulk (under dry argon at $70{ }^{\circ} \mathrm{C}$ for 14 days). After the polyreaction time was complete, the mixture was dissolved in $\mathrm{CH}_{2} \mathrm{Cl}_{2}$ and the insoluble enzyme was removed by filtration. Next, the obtained solution was washed with cold $\mathrm{MeOH}$ using vigorous stirring. The operation was repeated three times [31]. The final products (poly( $\varepsilon$-caprolactone) diols, PCL diols) were dried in vacuo at room temperature for $48 \mathrm{~h}$.

\section{FTIR and NMR Data}

${ }^{1} \mathrm{H}$ NMR ( $\left.\mathrm{CDCl}_{3}, \delta, \mathrm{ppm}\right): 4.03$ [2H, t, $\left.-\mathrm{CH}_{2} \mathrm{CH}_{2} \mathrm{CH}_{2} \mathrm{CH}_{2} \mathrm{CH}_{2} \mathrm{OC}(\mathrm{O})-\right], 2.27$ [2H, t, $-\mathrm{CH}_{2} \mathrm{CH}_{2} \mathrm{CH}_{2}$ $\mathrm{CH}_{2} \mathrm{CH}_{2} \mathrm{COO}-$ ], 1.61 [4H, m, $-\mathrm{CH}_{2} \mathrm{CH}_{2} \mathrm{CH}_{2} \mathrm{CH}_{2} \mathrm{CH}_{2} \mathrm{COO}-$ ], 1.36 [2H, m, $-\mathrm{CH}_{2} \mathrm{CH}_{2} \mathrm{CH}_{2} \mathrm{CH}_{2} \mathrm{CH}_{2} \mathrm{COO}-$ ];

${ }^{13} \mathrm{C}$ NMR $\left(\mathrm{CDCl}_{3}, \delta, \quad \mathrm{ppm}\right): 173.3 \quad[-\mathrm{C}(\mathrm{O}) \mathrm{O}-], 63.9 \quad\left[-\mathrm{CH}_{2} \mathrm{CH}_{2} \mathrm{CH}_{2} \mathrm{CH}_{2} \mathrm{CH}_{2} \mathrm{OC}(\mathrm{O})-\right], 33.8$ [ $-\mathrm{CH}_{2} \mathrm{CH}_{2} \mathrm{CH}_{2} \mathrm{CH}_{2} \mathrm{CH}_{2} \mathrm{COO}-$ ], 28.1 [ $-\mathrm{CH}_{2} \mathrm{CH}_{2} \mathrm{CH}_{2} \mathrm{CH}_{2} \mathrm{CH}_{2} \mathrm{OC}(\mathrm{O})-$ ], 25.4 [ $-\mathrm{CH}_{2} \mathrm{CH}_{2} \mathrm{CH}_{2} \mathrm{CH}_{2} \mathrm{CH}_{2} \mathrm{COO}-$ ], $24.4\left[-\mathrm{CH}_{2} \mathrm{CH}_{2} \mathrm{CH}_{2} \mathrm{CH}_{2} \mathrm{CH}_{2} \mathrm{COO}-\right]$;

FTIR (KBr, cm $\left.{ }^{-1}\right): 2950\left(\mathrm{vas}_{\mathrm{as}} \mathrm{CH}_{2}\right), 2865\left(\mathrm{v}_{\mathrm{s}} \mathrm{CH}_{2}\right), 1730(\mathrm{vC}=\mathrm{O}), 1240$ (vas $\left.\mathrm{COC}\right), 1190$ (vOC-O), $1170\left(v_{\mathrm{s}} \mathrm{COC}\right)$.

\subsection{Synthesis of Polyurethanes}

The PUs were prepared following a two-step, pre-polymer synthesis method. The isocyanate index was about 1.05. First, all the reactants (HMDI, PEAD diol, PCL diol, BD) were dried in vacuo for $1 \mathrm{~h}$ at $60{ }^{\circ} \mathrm{C}$. The reactor was vacuumed and then purged with argon. The polyols and catalyst (DABCO) were first mixed at $80-100{ }^{\circ} \mathrm{C}$ in a three-necked flask equipped with a stirrer and thermometer. Next, HMDI was added to the reaction mixture and all the components were mixed vigorously for about 5 min. The temperature of the reactor was reduced to $70-80{ }^{\circ} \mathrm{C}$. A chain extender (BD) was then slowly added to the reaction mixture. The reaction was kept at $70-80{ }^{\circ} \mathrm{C}$ for $3 \mathrm{~h}$. Next, the product was 
conditioned in vacuo at $50{ }^{\circ} \mathrm{C}$ for $24 \mathrm{~h}$. The synthesized PUs were dissolved in DMSO and precipitated into distilled water. Next, precipitated PUs were dried in vacuo at $40-50{ }^{\circ} \mathrm{C}$ for one week.

FTIR and NMR Data

${ }^{1} \mathrm{H}$ NMR (DMSO-d $6, \delta, \mathrm{ppm}$ ): 6.87 [1H, s, -OC(O)NH-], $4.33\left[4 \mathrm{H}, \mathrm{t},-\mathrm{NHCOO}-\mathrm{CH}_{2} \mathrm{CH}_{2} \mathrm{CH}_{2} \mathrm{CH}_{2}\right.$ $\mathrm{OC}(\mathrm{O}) \mathrm{NH}-], 3.91\left[2 \mathrm{H}, \mathrm{t},-\mathrm{NHC}(\mathrm{O}) \mathrm{OCH} \mathbf{H}_{2}-\right], 3.78-3.65\left[4 \mathrm{H}, \mathrm{m},-\mathrm{NHCOO}-\mathrm{CH}_{2} \mathrm{CH}_{2} \mathrm{CH}_{2} \mathrm{CH}_{2} \mathrm{OC}(\mathrm{O})\right.$ $\mathrm{NH}-$ and $4 \mathrm{H}, \mathrm{t},-\mathrm{C}(\mathrm{O}) \mathrm{OCH}_{2} \mathrm{CH}_{2} \mathrm{O}-$ ], 3.17 [2H, t, $-\mathrm{CH}_{2} \mathrm{NHC}(\mathrm{O}) \mathrm{O}-$ ], 2.30-2.25 [2H, t, $\mathrm{CH}_{2} \mathrm{CH}_{2} \mathrm{COO}-$ ], 1.60-1.50 [2H, m, $-\mathrm{CH}_{2} \mathrm{CH}_{2} \mathrm{NHC}(\mathrm{O}) \mathrm{O}-$ and $4 \mathrm{H}, \mathrm{m},-\mathrm{CH}_{2} \mathrm{CH}_{2} \mathrm{CH}_{2} \mathrm{CH}_{2} \mathrm{CH}_{2} \mathrm{COO}-$ ], 1.40-1.30 [2H, m, $-\mathrm{CH}_{2} \mathrm{CH}_{2} \mathrm{CH}_{2} \mathrm{NHC}(\mathrm{O}) \mathrm{O}-$ and $2 \mathrm{H}, \mathrm{m},-\mathrm{CH}_{2} \mathrm{CH}_{2} \mathrm{CH}_{2} \mathrm{CH}_{2} \mathrm{CH}_{2} \mathrm{COO}-$ ];

${ }^{13} \mathrm{C}$ NMR (DMSO-d $\left.6, \delta, \mathrm{ppm}\right): 173.1$ [-C(O)O-], 156.1 [-NHC(O)O-], $63.3\left[-\mathrm{OC}(\mathrm{O}) \mathrm{CH}_{2}-\right], 33.8$ [- $\mathrm{CH}_{2} \mathrm{CH}_{2} \mathrm{CH}_{2} \mathrm{CH}_{2} \mathrm{CH}_{2} \mathrm{COO}-$ ], 29.2 [- $\mathrm{CH}_{2} \mathrm{NHC}(\mathrm{O}) \mathrm{O}-$ ], 28.5 [-NHC(O)NHCH $\mathrm{NH}_{2}$ ], 24.9-25.9 [- $\mathrm{CH}_{2}-$ ];

FTIR (KBr, cm $\left.{ }^{-1}\right): 3323(\mathrm{vN}-\mathrm{H}), 2938\left(\mathrm{v}_{\mathrm{as}} \mathrm{CH}_{2}\right), 2859\left(\mathrm{v}_{\mathrm{s}} \mathrm{CH}_{2}\right), 1734(\mathrm{vC}=\mathrm{O}$, polyester $)$, $1623(v \mathrm{C}=\mathrm{O}$, ester), $1535(\delta \mathrm{N}-\mathrm{H}$, urethane).

\subsection{Cytotoxicity Assays}

The luminescent bacteria $V$. fischeri and two ciliated protozoans S. ambiguum and T. termophila were used to evaluate the cytotoxicity of the obtained PCL diols and PUs. The cytotoxicity tests were carried out according to procedures described in our earlier papers $[32,33]$.

\subsection{Composite Production}

The previously synthesized PUs were first dissolved in DMSO at a concentration of $10 \%-20 \%$ $(w / v)$. Next, the PUs solution were mixed with HA. Pores were created by mixing the mixture of PUs and $\mathrm{HA}$ with $0.5 \mathrm{~g}$ of $\mathrm{NaCl}$ crystals per $1.5 \mathrm{~g}$ of PU. The PU/salt mixtures were poured into a mould. Next, the mould were dried in vacuo at $40-50{ }^{\circ} \mathrm{C}$ for $24-48 \mathrm{~h}$. The samples were washed for $24 \mathrm{~h}$ in distilled water to remove $\mathrm{NaCl}$. The composite samples were later dried in vacuo at room temperature for about one week.

\subsection{Clodronate Impregnation of the Polyurethane Composites}

CLO was incorporated into the PU composites by immersing the material into an aqueous drug solution of known concentration. The solution was pulled into the pores of the biomaterials by repeated five-cycles of vacuum/argon. PU composites were dried in vacuo at room temperature until the weight of the impregnated materials remained unchanged. The gain in weight of the PU composites following impregnation was taken as the weight of the CLO incorporated into the biomaterials.

\subsection{Clodronate Release from the Composites}

The composite BPDDS were incubated in a phosphate buffer solution (PBS) (pH 7.4) at a ratio of $15 \mathrm{mg}$ of composite to $1 \mathrm{~mL}$ of buffer at $37{ }^{\circ} \mathrm{C}$. The mixture was stirred under constant agitation (50 cycles/min) and a sample was removed at selected intervals followed by fresh buffer replacement. The quantity of the released CLO was determined from the calibration curve previously obtained under 
the same conditions and analysed by means of the high performance liquid chromatography with charged aerosol detector (HPLC CAD) method.

\subsection{Degradation Test}

The hydrolytic degradation of the PUs and PU composites was measured by immersion for eight weeks in a PBS at $37^{\circ} \mathrm{C}$. After a certain period, the biomaterials were completely dried in a vacuum oven at $35^{\circ} \mathrm{C}$. Three individual experiments were performed in the degradation test, and then the average value was calculated. The degree of degradation was determined from the weight loss $\left(W_{L}\right)$ of the polymeric samples according to the equation: $W_{L}=\left[\left(W_{0}-W_{\mathrm{d}}\right) / W_{0}\right] \times 100(\%)$, where $W_{0}$ is the initial weight of the polymer sample and $W_{\mathrm{d}}$ is the weight of the dry polymer sample after degradation.

\subsection{Measurements}

${ }^{1} \mathrm{H}$ and ${ }^{13} \mathrm{C}$ NMR spectra of the PCL diols and PUs were recorded on a Varian $300 \mathrm{MHz}$ spectrometer using $\mathrm{CDCl}_{3}$ or $\mathrm{DMSO}_{-} \mathrm{d}_{6}$ as a solvent. Tetramethylsilane was served as the internal standard. The FTIR spectra were measured from KBr pellets (PerkinElmer spectrometer, PerkinElmer, Warsaw, Poland).

The molar mass and molar mass distributions of the PCL diols were determined using a GPC instrument (GPC Max + TDA 305, Viscotek, Malvern, UK) equipped with Jordi DVB Mixed Bed columns (one guard and two analytical, Viscotek) at $30{ }^{\circ} \mathrm{C}$ in $\mathrm{CH}_{2} \mathrm{Cl}_{2}$ (HPLC grade, Sigma-Aldrich, Poznań, Poland) at a flow rate of $1 \mathrm{~mL} / \mathrm{min}$ with RI detection and calibration based on narrow PS standards (ReadyCal Set, Fluka). The results were processed using the OmniSEC software (ver. 4.7) (Viscotek).

The MALDI-TOF MS spectra were performed in linear mode on an ultrafleXtreme ${ }^{\mathrm{TM}}$ (Bruker Daltonics, Poznań, Poland) mass spectrometer using a nitrogen gas laser and HABA as a matrix. The polymer samples were dissolved in tetrahydrofuran (THF) $(5 \mathrm{mg} / \mathrm{mL})$ and mixed with a solution of HABA.

Polymer viscosity was measured in DMF (at $30{ }^{\circ} \mathrm{C}$ ) on a Stabinger Viscometer SVM 3000 (Anton Paar's, Graz, Austria). The concentrations of the PU solutions in DMF were $0.2 \%, 0.4 \%, 0.6 \%, 0.8 \%$ and $1 \%$. The viscosity-average molecular weight was calculated with the Mark-Houwink equation using the following constants: $\mathrm{K}=6.80 \times 10^{-5} \mathrm{dL} / \mathrm{g}$ and $\alpha=0.86$ [34].

The surface morphologies were studied by scanning electron microscope (SEM, LEO 435VP (Zeiss, Jena, Germany)) so as to compare them with the initial morphologies.

The fail stress $\left(F_{S}\right)$, stress at 100\% elongation $\left(S_{100}\right)$, elongation at break $(\varepsilon)$ and Shore'a hardness $\left(S h_{H}\right)$ of the PU samples were measured using a Zwick model 1445 tester. $F_{S}, S_{100}$ and $\varepsilon$ were determined according to national standard PN-ISO 37:2007. $S h_{H}$ was determined according to national standard PN-80/C-04238 [35].

The density and porosity values of the PU composites were measured by the liquid displacement method [36]. Ethanol (EtOH) was used as the displacement liquid. A dry composite sample was placed in a cylinder filled with a predetermined volume of EtOH $\left(V_{1}\right)$. Next, the cylinder was placed in vacuo for $20 \mathrm{~min}$. The total volume of $\mathrm{EtOH}$ containing the composite sample was recorded as $V_{2}$ and the 
residual $\mathrm{EtOH}$ volume was recorded as $V_{3}$. Three individual measurements were performed and then the average value was calculated.

The amount of open pores in the PU composites $(P)$ was calculated according to the following equation:

$$
P(\%)=\left(V_{1}-V_{3}\right) /\left(V_{2}-V_{3}\right) \times 100 \%
$$

where $\left(V_{2}-V_{3}\right)$ denotes the total volume of the composite sample and $\left(V_{1}-V_{3}\right)$ denotes the volume of ethanol retained in the composite sample.

The density of the composite $(d)$ was expressed as:

$$
d=W /\left(V_{2}-V_{3}\right)
$$

where $W$ refers to the weight of the sample.

The quantity of the released CLO was analysed by means of HPLC CAD using the UHPLC Dionex Ultimate 3000 analytical system with a CAD detector. Chromatographic separations were carried out using the Luna C8 column $(250 \times 4.6 \mathrm{~mm}, 5 \mu \mathrm{m})$. The calibration curve was obtained by the analysis of different concentrations of CLO in PBS solutions $(0.05-2.00 \mathrm{mg} / \mathrm{mL})$. The analytical method was validated by the Pharmaceutical Research Institute in Poland.

\section{Conclusions}

New porous composite bisphosphonate delivery systems were prepared from biodegradable polyurethanes and nanocrystalline hydroxyapatite. The obtained polymer matrices were non-toxic. The rates of clodronate release were shown to be directly dependent upon the nature of the obtained polyurethanes and the porosity of the composites. The results demonstrate that the polyurethane/hydroxyapatite composites are promising materials for the controlled release of clodronate and they can find practical applications as effective medium- or long-term implantation drug delivery systems.

\section{Acknowledgments}

This work was supported by the research programme (Project MNiSzW-2011/03/D/ST5/05793: "Synthesis and characterization of polymer-apatite composite containing selenium and bisphosphonates") of the Ministry of Science and Higher Education in Poland.

\section{Author Contributions}

The contributions of the respective authors are as follows: Joanna Kolmas and Marcin Sobczak gave the concept of work, interpreted the results and wrote the whole article, made discussion and conclusion. Ewa Olędzka and Cezary Dębek participated in all steps of the research, helped in the biomaterials synthesis and writing of the paper. Grzegorz Nałęcz-Jawecki performed cytotoxicity analysis. All authors have contributed to seen and approved the manuscript.

\section{Conflicts of Interest}

The authors declare no conflict of interest. 


\section{References}

1. Coleman, R.E. Metastatic bone disease: Clinical features, pathophysiology and treatment strategies. Cancer Treat. Rev. 2001, 27, 165-176.

2. Holen, I.; Coleman, R.E. Bisphosphonates as treatment of bone metastases. Curr. Pharm. Des. 2010, 16, 1262-1271.

3. Coleman, R.E. Bisphosphonates: Clinical experience. Oncologist 2004, 9, 14-27.

4. Lipton, A. Pathophysiology of bone metastases: How this knowledge may lead to therapeutic intervention. J. Support. Oncol. 2004, 2, 205-220.

5. Von Moos, R. Ibandronate provides efficacy and safety in the treatment of metastatic bone disease. Eur. J. Cancer Suppl. 2006, 4, 13-18.

6. Russell, R.G.; Watts, N.B.; Ebetino, F.H.; Rogers, M.J. Mechanisms of action of bisphosphonates: Similarities and differences and their potential influence on clinical efficacy. Osteoporos. Int. 2008, 19, 733-759.

7. Russell, R.G. Bisphosphonates: The first 40 years. Bone 2011, 49, $2-11$.

8. Padalecki, S.S.; Carreon, M.; Grubbs, B.; Cui, Y.; Guise, T.A. Androgen deprivation enhances bone loss and prostate cancer metastases to bone: Prevention by zoledronic acid. Oncology 2003, 17 (Suppl.), 32-54.

9. Rosen, L.S.; Gordon, D.; Kaminski, M.; Howell, A.; Belch, A.; Mackey, J.; Apffelstaedt, J.; Hussein, M.A. Long-term efficacy and safety of zoledronic acid compared with pamidronate disodium in the treatment of skeletal complications in patients with advanced multiple myeloma or breast cancer: A randomized, double-blind, multicenter, comparative trial. Cancer 2003, 98, 1735-1744.

10. Barret-Lee, P.; Casbard, A.; Abraham, J.; Hood, K.; Coleman, R.; Simmonds, P.; Timmins, H.; Wheatley, D.; Grieve, R.; Griffiths, G.; et al. Oral ibandronic acid versus intravenous zoledronic acid in treatment of bone metastases from breast cancer: A randomised, open label, non-inferiority phase 3 trial. Lancet Oncol. 2014, 15, 114-122.

11. Tanvetyanon, T.; Stiff, P.J. Management of the adverse effects associated with intravenous bisphosphonates. Ann. Oncol. 2006, 17, 897-907.

12. Uhrich, K.E.; Cannizzaro, S.M.; Langer, R.S.; Shakesheff, K. Polymeric systems for controlled drug release. Chem. Rev. 1999, 99, 3181-3198.

13. Ouchi, T.; Ohya, Y. Macromolecular prodrugs. Prog. Polym. Sci. 1995, 20, 211-257.

14. Sobczak, M.; Olędzka, E.; Kołodziejski, W.; Kuźmicz, R. Pharmaceutical application of polymers. Polimery 2007, 52, 411-420.

15. Giger, E.V.; Castagner, B.; Leroux, J.-C. Biomedical applications of bisphosphonates. J. Control. Release 2013, 167, 175-188.

16. Karrholm, J.; Borssen, B.; Lowenhielm, G.; Snorrason, F. Does early micromotion of femoral stem prostheses matter? 4-7-Year stereoradiographic follow-up of 84 cemented prostheses. J. Bone Jt. Surg. Br. 1994, 76, 912-917.

17. Cremers, S.; Papapoulos, S. Pharmacology of bisphosphonates. Bone 2011, 49, 42-49. 
18. Katsumi, H.; Takashima, M.; Sano, J.-I.; Nishiyama, K.; Kitamura, N.; Sakane, T.; Hibi, T.; Yamamoto, A. Development of polyethylene glycol-conjugated alendronate, a novel nitrogen-containing bisphosphonate derivative: Evaluation of absorption, safety, and effects after intrapulmonary administration in rats. J. Pharm. Sci. 2011, 100, 3783-3792.

19. Bellido, T.; Plotkin, L.I. Novel actions of bisphosphonates in bone: Preservation of osteoblast and osteocyte viability. Bone 2011, 49, 50-55.

20. Gutman, D.; Golomb, G. Liposomal alendronate for the treatment of restenosis. J. Control. Release 2012, 161, 619-627.

21. Zeisberger, S.M.; Odermatt, B.; Marty, C.; Zehnder-Fjallman, A.H.M.; Ballmer-Hofer, K.; Schwendener, R.A. Clodronate-liposome-mediated depletion of tumour associated macrophages: A new and highly effective antiangiogenic therapy approach. Br. J. Cancer 2006, 95, 272-281.

22. Salzano, G.; Marra, M.; Porru, M.; Zappavigna, S.; Abbruzzese, A.; la Rotonda, M.I.; Leonetti, C.; Caraglia, M.; de Rosa, G. Self-assembly nanoparticles for the delivery of bisphosphonates into tumors. Int. J. Pharm. 2011, 403, 292-297.

23. Wang, G.; Mostafa, N.Z.; Incani, V.; Kucharski, C.; Uludag, H. Bisphosphonate decorated lipid nanoparticles designed as drug carriers for bone diseases. J. Biomed. Mater. Res. A 2012, 100, 684-693.

24. Cherng, J.Y.; Houa, T.Y.; Shih, M.F.; Talsma, H.; Hennink, W.E. Polyurethane-based drug delivery systems. Int. J. Pharm. 2013, 450, 145-162.

25. Errassifi, F.; Sarda, S.; Barroug, A.; Legrouri, A.; Sfihi, H.; Rey, C. Infrared, Raman and NMR investigations of risedronate adsorption on nanocrystalline apatites. J. Colloid Interface Sci. 2014, 420, 101-111.

26. Iafisco, M.; Palazzo, B.; Falini, G.; di Foggia, M.; Bonora, S.; Nicolis, S.; Casella, L.; Roveri, N. Adsorption and conformational change of myoglobin on biomimetic hydroxyapatite nanocrystals functionalized with alendronate. Langmuir 2008, 24, 4924-4930.

27. Josse, S.; Faucheux, C.; Soueidan, A.; Grimandi, G.; Massiot, D.; Alonso, B.; Janvier, P.; Laïb, S.; Pilet, P.; Gauthier, O.; et al. Novel materials for bisphosphonates delivery. Biomaterials 2005, 26, 2073-2080.

28. Cukrowski, I.; Popović, L.; Barnard, W.; Paul, S.O.; van Royen, P.H.; Liles, D.C. Modeling and spectroscopic studies of bisphosphonate-bone interactions. The Raman, NMR and crystallographic investigations of Ca-HEDP complexes. Bone 2007, 41, 668-678.

29. Alghamdi, H.S.; Bosco, R.; Both, S.K.; Iafisco, M.; Leeuwenburgh, S.C.G.; Jansen, J.A.; van den Beucken, J.J.J.P. Synergistic effect of bisphosphonates and calcium phosphate nanoparticles on peri-implant bone responses in osteoporotic rats, Biomaterials 2014, 35, 5482-5490.

30. Pascaud, P.; Errassifi, F.; Brouillet, F.; Sarda, S.; Barroug, A.; Legrouri, A.; Rey, C. Adsorption on apatitic calcium phosphates for drug delivery: Interaction with bisphosphonates molecules. J. Mater. Sci. Mater. Med. 2014, doi:10.1007/s10856-014-5218-0.

31. Sobczak, M. Enzyme-catalyzed ring-opening polymerization of cyclic esters in the presence of poly(ethylene glycol). J. Appl. Polym. Sci. 2012, 125, 3602-3609. 
32. Sobczak, M.; Dębek, C.; Olędzka, E.; Nałęcz-Jawecki, G.; Kołodziejski, W.L.; Rajkiewicz, M. Segmented polyurethane elastomers derived from aliphatic polycarbonate and poly(ester-carbonate) soft segments for biomedical applications. J. Polym. Sci. A Polym. Chem. 2012, 50, 3904-3913.

33. Sobczak, M.; Nałęcz-Jawecki, G.; Kołodziejski, W.L.; Goś, P.; Żółtowska, K. Synthesis and study of controlled release of ofloxacin from polyester conjugates. Int. J. Pharm. 2010, 402, 37-43.

34. Gorna, K.; Gogolewski, S. In vitro degradation of novel medical biodegradable aliphatic polyurethanes based on $\varepsilon$-caprolactone and Pluronics ${ }^{\circledR}$ with various hydrophilicities. Polym. Degrad. Stab. 2002, 75, 113-122.

35. Sobczak, M.; Dębek, C.; Goś, P. Preparation and mechanical properties of PCL-based polyurethanes as potential biomaterials for short-term applications. E-Polymers 2010, 10, 1661-1669.

36. Asefnejad, A.; Khorasani, M.T.; Behnamghader, A.; Farsadzadeh, B.; Bonakdar, S. Manufacturing of biodegradable polyurethane scaffolds based on polycaprolactone using a phase separation method: Physical properties and in vitro assay. Int. J. Nanomed. 2011, 6, 2375-2384.

(C) 2014 by the authors; licensee MDPI, Basel, Switzerland. This article is an open access article distributed under the terms and conditions of the Creative Commons Attribution license (http://creativecommons.org/licenses/by/3.0/). 